Note

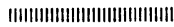

\title{
Radiolysis of Active Sites of Gibberellic Acid Molecule in Dilute Solution ${ }^{\dagger}$
}

\author{
Itsuo KUROBANE and Hikoyuki YAMAGUCHI \\ Laboratory of Radiation Genetics, Faculty of Agriculture, \\ The University of Tokyo, Tokyo 113, Japan
}

Received June 10, 1975

\section{Introduction}

Gibberellic acids are very significant as inducers of synthesis of enzymes essential for germination of cereal seeds. Sideris et al. ${ }^{1,2)}$ demonstrated that the biological activity of gibberellic acid was destructed when its aqueous solutions were irradiated with relatively low doses of gamma rays. And, the protection experiments ${ }^{2)}$ with $\mathrm{OH}$ radical scavengers, such as potassium iodide and $p$-aminobenzoic acid, suggested that the inactivation of the gibberellic acid by gamma-irradiation might be attributed to an indirect effect through reactions with $\mathrm{OH}$ radicals originating presumably from the radiolysis of water. Furthermore, they speculated that the reduced absorbance of the gibberellic acid molecule at the $\gamma$-lactone ring coupled with its reduced biological activity, following irradiation.

This communication presents further evidence for the in vitro destruction of $\gamma$ lactone ring of gibberellic acid by gamma irradiation, leading presumably to reduction of the biological activity of the gibberellic acid.

\section{Materials and Methods}

Dwarf rice (Oryza sativa cv. Tanginbozu) and barley(Hordeum vulgare cv. Fuji 2-Jyo) seeds were used for gibberellic acid bioassay as described by Ogawa ${ }^{3)}$ and Jones and Varner ${ }^{1)}$, respectively.

Gibberellic acid $\left(90 \% \mathrm{GA}_{6}\right.$, the rest, main- ly other gibberellins) was kindly given by Kyowa Hakko Co., Ltd. Prior to experiments, gibberellic acid was purified by crystallization. Solutions of $100 \mathrm{ppm} \mathrm{GA}_{3}$, which were dissolved into the twice distilled water, were irradiated at $25^{\circ} \mathrm{C}$ with 0,50 , $100,150,250,500$ and $1,000 \mathrm{kR}$ of gamma rays from ${ }^{13 i} \mathrm{Cs}$ source. The exposure time was $62 / 3$ hours.

After irradiation, the $\mathrm{pH}$ of $\mathrm{GA}_{3}$ solution was adjusted to 7.0 and then the solution was partitioned three times against equal volumes of ethyl-acetate to obtain the neutral ethyl-acetate fraction. The $\mathrm{pH}$ of the water phase was adjusted to 3.0 and then it was partitioned again against ethyl-acetate. Thus, the acidic ethyl-acetate fraction was obtained. The remaining water phase was then partitioned against $n$-butanol to obtain the acidic butanol fraction. Each fraction was dried over anhydrous sodium sulfate and evaporated to dryness under reduced pressure at $40^{\circ} \mathrm{C}$.

Each fraction was spotted on thin layer of silica gel G (0.3-0.4 $\mathrm{mm}$ in thickness), and developed in a solvent system of chloroform, ethyl acetate and acetic acid (60:40:5, v/v) for the neutral and acidic ethyl-acetate fractions, as well as in a solvent system of chloroform, methanol, acetic acid and water (40:15:3:2, v/v) for the acidic butanol fraction. Chromatograms were sprayed with $70 \%$

†希薄溶液におけるジベレリン分子活性部位の放射 線分解。黑羽簃夫, 山口彦之: 東京大学農学部放 射線遗伝学教等 (東京都文京区弥生1-1-1) 
sulfuric acid vapor, heated for about 10 minutes at $100^{\circ} \mathrm{C}$ and separated into several fractions using UV-absorption. Each fraction was extracted with $60 \%$ acetone-water solution and evaporated to dryness under reduced pressure at $40^{\circ} \mathrm{C}$.

Infrared and mass spectra were determined after methylation of the fractions separated by TLC and authentic $\mathrm{GA}_{3}$ with diazomethane.

\section{Results}

Five fluorescent spots in addition to that of $\mathrm{GA}_{3}$ were detected on the chromatogram of the acidic ethyl-acetate fraction (Fig. 1),

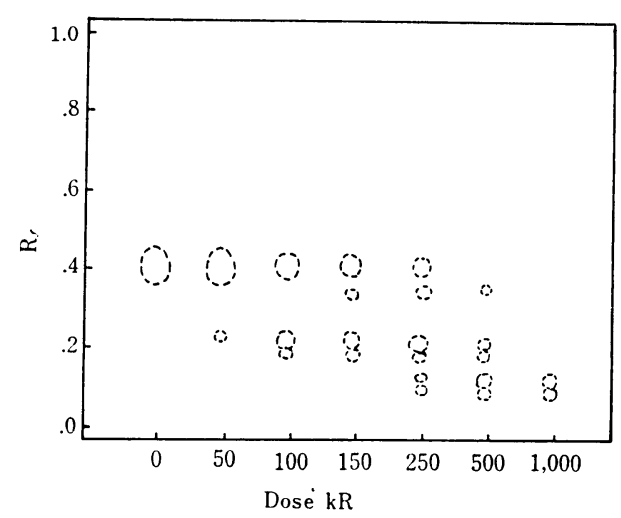

Fig. 1 TL chromatogram of the acidic ethylacetate fraction partitioned from the 100 ppm $\mathrm{GA}_{3}$ solution after gamma irradiation.

while no fluorescent spot on the chromatograms of the other fractions. Newly found spots were termed F-I, II, III, IV and V in the order of $R f$ value. Because F-II was produced even with the lowest dose used, $50 \mathrm{kR}$, and the other fractions did not appear until using the higher doses, it seemed to be the primary radiolytic product of $\mathrm{GA}_{3}$.

The fluorescent colors of F-II, IV and V were very similar to that of $\mathrm{GA}_{3}$, namely light blue. However, those of F-I and III were a little more greenish than that of $\mathrm{GA}_{3}$.

After one litre of $100 \mathrm{ppm} \mathrm{GA}_{3}$ solution, dissolved $100 \mathrm{mg} \mathrm{GA}_{3}$ in one litre of the twice distilled water, was irradiated with $100 \mathrm{kR}$ of gamma rays, the amount of the products in each fraction, partitioned against ethylacetate or $n$-butanol, was weighed. The result showed that the yields of the neutral and acidic ethyl-acetate fractions, and the acidic butanol fraction were $0.8,85.5$ and $3.6 \mathrm{mg}$, respectively.

The biological activities of the products, separated by TLC, in the acidic ethyl-acetate fraction was completely destroyed by gamma-irradiation with $100 \mathrm{kR}$.

The absorption peak at $1770 \mathrm{~cm}^{-1}$ in the inf rared spectrum of F-II was strongly reduced after irradiation of $100 \mathrm{kR}$.

Mass spectrum of F-II revealed the highest molecular ion peak at $m / e 330$ (Fig. 3).

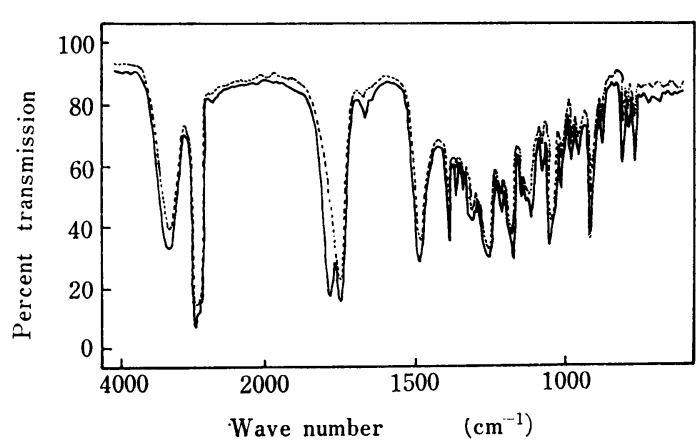

Fig. 2 Infrared spectra of F-II (dotted line) separated from irradiated and non-irradiated $\mathrm{GA}_{3}$ (solid line).

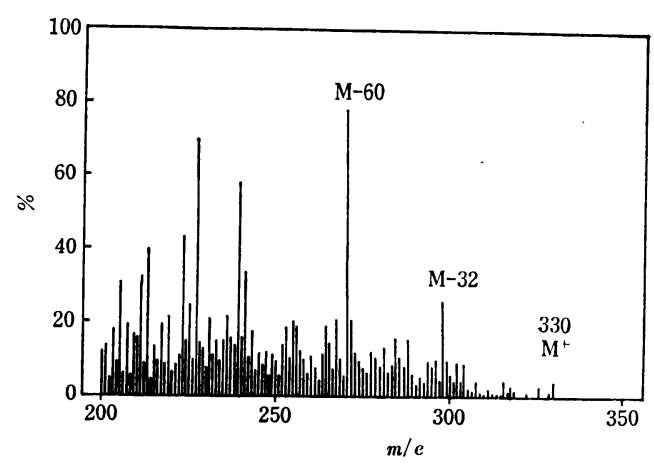

Fig. 3 Mass spectrum of F-II separated from irradiated $\mathrm{GA}_{3}$.

F-II together with the $\mathrm{GA}_{3}$ derivatives such as gibberic, allogibberic and epiallogibberic acids were spotted on one and the same thin layer and developed using several different solvent systems. No derivative was correspondent to F-II. 


\section{Discussion}

The results of the TLC of the acidic ethylacetate fraction indicated that at least five fluorescent spots were yielded as the radiolytic products of $\mathrm{GA}_{3}$, and suggested that F-II might be the primary product (Fig. 1). Inf rared (Fig. 2) and mass (Fig. 3) spectra of F-II suggested that the $\gamma$-lactone ring of gibberellic acid was destructed by gamma radiation. Namely, F-II failed to show any significantly strong ion peak at $\mathrm{M}-44\left(\mathrm{CO}_{2}\right)$, $\mathrm{M}-46(\mathrm{HCOOH})$ or $\mathrm{M}-62\left(\mathrm{H}_{2} \mathrm{O}, \mathrm{CO}_{2}\right)$ presumably due to the elimination of the $\gamma$-lactone ring ${ }^{5)}$.

On the other hand, the basic structure of $\mathrm{GA}_{3}$ molecule, that is gibberellane, seems to be more resistant to gamma rays, because the absorbance peaks at 1670 and $880-900$ $\mathrm{cm}^{-1}$ were not appreciably affected (Fig. 2).

In conclusion, the present investigation suggests that $\mathrm{GA}_{3}$ molecule in aqueous solution is inactivated by gamma rays, primarily through degradation of the $\gamma$-lactone ring, and that, then, the loss of the biological activities of the radiolytic products is ascribable to the initial destruction of the $\gamma$ lactone ring with gamma radiation.

\section{Acknowledgement}

Valuable discussion of Professors S. Tamura and N. Takahashi is greatly acknowledged.

\section{References}

1) E.G. Sideris, A. Kleinhofs and R.A. Nilan: Radiation Botany, 9, 349 (1969)

2) E.G. Sideris, M.M. Nawar and R.A. Nilan: Radiation Botany, 11, 209 (1971)

3) Y. Ogawa: Plant and Cell Physiol., 4, 227 (1967)

4) R.L. Jones and J.E. Varner: Planta, 72, 155 (1967)

5) N. Takahashi: in "Gibberellins" (ed. S. Tamura), Univ. of Tokyo Press, Tokyo, p. 59 (1969) 